\title{
The legacy of Jules Gonin: one hundred years of identifying and treating retinal breaks
}

\author{
Stephen G. Schwartz ${ }^{1} \cdot$ Robert Garoon ${ }^{2} \cdot$ William E. Smiddy ${ }^{2} \cdot$ Harry W. Flynn $\mathrm{Jr}^{2}$
}

Received: 16 April 2018 / Accepted: 20 April 2018 / Published online: 28 April 2018

(C) Springer-Verlag GmbH Germany, part of Springer Nature 2018

Over the past 100 years, rhegmatogenous retinal detachment (RD) has evolved from a poorly understood and untreatable disease to one in which single-operation success rates exceed 90\% with modern techniques [1]. A key step in this progress was the recognition that rhegmatogenous RDs are by definition caused by one or more retinal breaks. This finding was first presented by Jules Gonin to the Swiss Ophthalmological Society in 1918 [2], making 2018 a very special 100-year anniversary of this observation.

The identification of retinal breaks as the cause of RD also allowed clinicians to perform prophylaxis. In the current issue, Garoon and colleagues review the outcomes of treatment in a large clinical series [3]. Retinopexy has been performed since Gonin's time using various modalities, including diathermy (which required scleral dissection) [4], xenon arc photocoagulation [5], cryopexy [6], and modern photocoagulation techniques [7].

Prophylaxis of retinal breaks has become standard treatment worldwide, although there is surprisingly little evidence in the peer-reviewed literature to support this practice. Clearly, some patients with retinal breaks do not progress to RD, indicating that treatment is not always necessary. In addition, a small but appreciable subset of treated patients may progress to RD despite treatment, indicating that RD cannot always be "prevented."

Over the years, certain clinical characteristics have been associated with relatively greater risk, including horseshoe tears (versus atrophic or operculated holes), the presence of posterior vitreous detachment, and the presence of symptoms such as

Stephen G. Schwartz

sschwartz2@med.miami.edu

1 Department of Ophthalmology, Bascom Palmer Eye Institute, University of Miami Miller School of Medicine, 3880 Tamiami Trail North, Naples, FL, USA

2 Department of Ophthalmology, Bascom Palmer Eye Institute, University of Miami Miller School of Medicine, 900 NW 17th Street, Miami, FL 33136, USA photopsias and floaters [8]. There may be other factors, as yet undetermined. For example, a review of 76 cases of RD in India reported a significantly greater incidence of RD during the months March, April, and May; the authors hypothesized that ambient weather conditions might be responsible [9].

Currently, there are no randomized clinical trials (RCTs) on prophylaxis of $\mathrm{RD}$. Two Cochrane Database systematic reviews - one on the treatment of asymptomatic retinal breaks and lattice degeneration [10] and one on the treatment of the fellow eye in patients with giant retinal tear [11] - each reported that no relevant RCTs could be identified. Another systematic review searched 2941 publications and identified "no data suitable for statistical analysis" [12].

The American Academy of Ophthalmology Preferred Practice Pattern Panel guidelines, most recently revised in 2014, are based primarily on expert consensus. The Panel suggested prompt treatment of acute symptomatic horseshoe tears and acute symptomatic dialyses, and observation of most other peripheral lesions [13]. The Panel based these recommendations partly on the basis of a 1973 series by Davis, who reviewed 222 eyes with $>1$ retinal breaks with or without "subclinical" RD, defined as a detachment that extended no further than 2 disc diameters posterior to the equator. Davis concluded that symptomatic horseshoe tears were associated with the highest risk of RD (30-50\%) [14].

In the current issue, a retrospective series of 401 eyes treated with photocoagulation for retinal breaks is reported [3]. Among these eyes, 75 (18.7\%) required additional treatment, of which about half was to re-treat the original break and about half was to treat a new (or previously unrecognized) break. RD occurred in $23(5.7 \%)$ of these eyes [14]. These results suggest that long-term follow-up of these patients remains important to achieve best outcomes.

As we celebrate the 100th anniversary of Gonin's contribution, the remarkable progress in the care of patients with retinal breaks is apparent. We hope that the next 100 years will feature advances in the early diagnosis and treatment of retinal breaks. 
Funding information The study was partially supported by NIH Center Core Grant P30EY014801 and an Unrestricted Grant from Research to Prevent Blindness.

\section{Compliance with ethical standards}

Conflict of interest Dr. Schwartz reports personal fees within the past 3 years from Alimera and Welch Allyn outside the submitted work. The other authors report no disclosures.

\section{References}

1. Schwartz SG, Flynn HW Jr, Mieler WF (2013) Update on retinal detachment surgery. Curr Opin Ophthalmol 24:255-261

2. Duke-Elder S, Dobree JH (1967) System of ophthalmology, Vol X: Diseases of the Retina. CV Mosby, St Louis, p 771

3. Garoon RE, Smiddy WE, Flynn HW Jr (2018) Treated retinal breaks: clinical course and outcomes. Graefes Arch Clin Exp Ophthalmol in press

4. Wilkinson CP, Rice TA (1997) Michels retinal detachment, 2e. CV Mosby, St. Louis, pp 303-305

5. Meyer-Schwickerath GR (1989) The history of photocoagulation. Aust N Z J Ophthalmol 17:427-434
6. Lincoff HA, McLean JM, Nano H (1964) Cryosurgical treatment of retinal detachment. Trans Am Acad Ophthalmol Otolaryngol 68: $412-432$

7. L'Esperance FA Jr (1969) The treatment of ophthalmic vascular disease by argon laser photocoagulation. Trans Am Acad Ophthalmol Otolaryngol 73:1077-1096

8. Byer NE (1994) Natural history of posterior vitreous detachment with early management as the premier line of defense against retinal detachment. Ophthalmology 101:1503-1513

9. Prabhu PB, Raju KV (2016) Seasonal variation in the occurrence of rhegmatogenous retinal detachment. Asia Pac J Ophthalmol 5:122126

10. Wilkinson CP (2014) Interventions for asymptomatic retinal breaks and lattice degeneration for preventing retinal detachment. Cochrane Database Syst Rev (9):CD003170. https://doi.org/10. 1002/14651858.CD003170.pub4

11. Ang GS, Townend J, Lois N (2012) Interventions for prevention of giant retinal tear in the fellow eye. Cochrane Database Syst Rev (2): CD006909. https://doi.org/10.1002/14651858.CD006909.pub3

12. Blindbaek S, Grauslund J (2015) Prophylactic treatment of retinal breaks - a systematic review. Acta Ophthalmol 93:3-8

13. American Academy of Ophthalmology Retina/Vitreous Panel (2014) Preferred Practice Pattern Guidelines. Posterior vitreous detachment, retinal breaks, and lattice degeneration. San Francisco, CA: American Academy of Ophthalmology; 2014. Available at: www.aao.org/ppp (accessed April 10, 2018)

14. Davis MD (1973) The natural history of retinal breaks without detachment. Trans Am Ophthalmol Soc 71:343-372 